\title{
Work-Related Musculoskeletal Disorders: Comparison of Data Sources for Surveillance
}

\author{
Barbara A. Silverstein, PhD, MPH,* Diana S. Stetson, PhD, \\ W. Monroe Keyserling, PhD, and Lawrence J. Fine, MD, DrPH
}

\begin{abstract}
Work-related upper extremity musculoskeletal disorders "associated with repeated trauma" account for more than 60\% of all newly reported occupational illness, 332,000 in 1994 according to the U.S. Department of Labor. These numbers do not include, for example, those disorders categorized as "injuries due to overexertion in lifting," approximately 370,000. Early identification of potential disorders and associated risk factors is needed to reduce these disorders. There are a number of possible methods for conducting surveillance for work-related musculoskeletal disorders (WMDs) based on health outcome: workers' compensation, sickness and accident insurance, OSHA 200 logs, plant medical records, selfadministered questionnaires, professional interviews, and physical examinations. In addition, hazard surveillance based on evaluation of job exposures to physical stressors by nonoccupational health personnel is possible. As part of a large labor-management-initiated intervention study to reduce the incidence of WMDs in four automotive plants, we were able to compare the strengths and limitations of each of these surveillance tools. University administered health interviews yielded the highest rate of symptoms; combined physical examinations plus interview (point prevalence) rates were similar to self-administered questionnaires (period prevalence) rates. Plant medical records yielded the lowest rate of WMDs. WMD status on self-administered questionnaire and on physical examination were associated with risk factor exposure scores. This study suggests that symptoms questionnaires and checklist-based hazard surveillance are feasible within the context of joint labormanagement ergonomics programs and are more sensitive indicators of ergonomic problems than pre-existing data sources. Am. J. Ind. Med. 31:600-608, 1997. ๑ 1997 Wiley-Liss, Inc.
\end{abstract}

KEY WORDS: ergonomics; occupational; musculoskeletal; surveillance; repetitive strain injury; cumulative trauma disorders; occupational overuse syndrome; work-related musculoskeletal disorders (WMDs)

\section{INTRODUCTION}

Work-related musculoskeletal disorders (WMDs) (e.g., carpal tunnel syndrome, tendinitis, epicondylitis, low back pain) primarily affect soft tissues. These disorders are also known as cumulative trauma disorders, repetitive motion

University of Michigan School of Public Health and Center for Ergonomics, Ann Arbor, MI.

*Correspondence to: Barbara Silverstein, Ph.D., Safety and Health Assessment and Research for Prevention, Washington State Department of Labor and Industries, P.O. Box 44330, Olympia, WA 98504- 4330.

Accepted for publication 22 October 1996 disorders, repetitive strain injury, occupational overuse syndromes, or occupational cervicobrachial disorders. The work environment and performance of work contribute significantly to the development, exacerbation, or acceleration of these multifactorial disorders and may impair working capacity [Armstrong et al., 1993]. Specific work-related activities associated with these disorders include repetitive or forceful exertions, static or awkward postures, and vibration (segmental vibration for upper limb disorders, such as carpal tunnel syndrome, and whole body vibration for neck and low back disorders) [Snook, 1978; Moore, 1992; Hagberg et al., 1992; Hagberg and Wegman, 1987; Stenlund et al., 1993; Rempel et al., 1992; Armstrong et al., 1987; Silverstein et al., 1987; Hagberg et al., 1995]. Based on

(c) 1997 Wiley-Liss, Inc. 
workers' compensation claims and OSHA $200 \log$ data, the reported incidence of these disorders, particularly of the upper limb, has been increasing dramatically since the early 1980s [U.S. Bureau of Labor Statistics, 1995] and affects workers in virtually every industry.

As part of a large labor-management initiated intervention study to reduce the incidence of WMDs, we were able to compare several surveillance data sources to determine some of the strengths and limitations of each data source. Others have noted the likely deficiencies of some of the possible data sources for a WMD surveillance system [Pollack and Keimig, 1991]. The design of an efficient surveillance system for WMDs should be based on the specific characteristics of the possible data sources. From a public health perspective, early identification of WMDs would be beneficial in order to identify and reduce work-related risk factors and, where appropriate, provide early treatment.

\section{MATERIALS AND METHODS}

Our study examined data from a variety of sources in four automotive plants that were in the early stages of implementing ergonomic programs to reduce WMDs. The workplaces included a pressed metal plant (Plant 1), two service parts plants (Plants 2 and 3), and an engine plant (Plant 4). The focus of these programs was on "shop-floor" ergonomics where hourly workers known as "ergonomic monitors," and their supervisors were trained by plant trainers to identify and solve ergonomic problems with support from departmental and plant level ergonomics committees. Ergonomic monitors were either chosen by their coworkers or volunteered for these part-time assignments along with their regular work activities.

Each plant chose two target departments in which to implement the ergonomics pilot program. Department selection was based on size, relative stability for the previous year, and/or the presence of current ergonomic concerns as perceived by the joint-labor management committees. Six different health data sources were compared for workers in these eight departments, as well as one exposure data source. Pre-existing data sources included workers' compensation data for lost time claims, personal medical benefits (sickness and accident) data, OSHA 200 log data, and plant medical department log data. New health data sources included self-administered symptoms questionnaires distributed by ergonomic monitors to their coworkers during initial job risk factor assessments, and standardized interview and physical examinations conducted by the university research team.

\section{Data Sources}

1. Workers' compensation: Indemnity claims were those accepted by the company (self-insured) as work related and involving more than 7 days of lost time. Criteria for inclusion were onset in one of the target departments between January 1, 1986 and May 31, 1989; the location of disorder was neck, shoulder, elbow/forearm, hand, wrist, finger, or low back, and nature of "injury" was overuse, strain/sprain, and repetitive motion (excluding slip, trip, fall). Specific diagnoses of carpal tunnel syndrome, tendinitis, tenosynovitis, epicondylitis, bursitis were also included where available. Incidence rates were calculated as (number of new cases $\times 200,000$ $\mathrm{hr}$ )/total work hours. Two hundred thousand hours is roughly equivalent to 100 worker-years, assuming that 2,000 hr are worked per employee per year. Although there were a number of "medical only" claims (not resulting in lost time) during this period, the vast majority of them had no associated diagnosis or body part listed, so these were excluded from further consideration.

2. Personal medical benefits: Sickness and accident data were maintained by a large private insurance carrier. The collective bargaining agreement provided sickness and accident benefits for workers' compensation-type cases if they were less than the requisite 7 days required by workers' compensation rules. We do not believe that this practice is common in other industries. Inclusion criteria were the same as for workers' compensation claims.

3. Mandated reporting: OSHA $200 \log$ information was abstracted for employees from the target departments between January 1, 1986 and May 31, 1989 who experienced incidents categorized as having a "strain/ sprain" or a disorder "due to repetitive motion." The state OSHA required reporting on the $200 \log$ for all workers who had more than first-aid treatment, restricted or transferred work or lost time.

4. Employer records: Plant medical records for all employees in the target departments were abstracted from employee charts for 1986-1988 and from computerized medical log files for 1988-1989. Research team members performed abstraction by searching for specific disorders (e.g., carpal tunnel syndrome, tendinitis) as well as nonacute problems within the anatomic areas of interest. Repeat visits for the same problem were recorded only once within a given year.

5. Self-reports: Self-administered symptoms questionnaires were distributed and collected by coworkers trained as ergonomic monitors during initial ergonomic program implementation between May 1987 and May 1988. Follow-up symptoms questionnaires were completed in one plant (Plant 3) in May 1989. At the same time, the ergonomic monitors used a job risk factor checklist to identify possible ergonomic problems affecting jobs in the target departments. The symptoms questionnaire inquired about demographic information; about repeated pain or discomfort within the previous year; and about the location, onset, type, frequency, symptom duration, symptom severity, treatment, and lost time. Detailed 
information was recorded for the self-perceived worst problem. In order to match with the other health data sources, name and social security number were requested. Body maps and questions regarding annual and current prevalence were taken from the Nordic Questionnaire [Kuorinka et al., 1987]. Data were entered into a database program by the ergonomics committee members. The case definition was symptoms occurring in the previous year at least 20 times or lasting at least one week and a discomfort score greater than 1 on a scale of $1-10$ scale $(10=$ unbearable $)$.

6. In-person assessments: University interviews and physical examinations were conducted by researchers during work time in the target departments at the beginning of program implementation in the department and 1-1.5 years later. The baseline university evaluation data were collected within 2-3 months of the baseline selfadministered symptoms questionnaire data. The structured interview asked many of the same questions as the selfadministered symptoms questionnaire but also included questions about health history, recreational activities, and psychosocial factors of work. The physical examination (conducted blinded to the interview) consisted of inspection and palpation; active, passive, and resisted motion testing; pinch and grip strength; 2-point discrimination; vibration threshold testing; and median and ulnar nerve conduction studies at the wrist. The case definition on interview was symptoms in the relevant region occurring in the previous year at least 20 times or lasting at least 1 week, with no acute traumatic onset or relevant systemic disease. The case definition on physical examination was that tendon-related disorders had no pain or limitation on passive range of motion but did have pain in the appropriate area made worse by resisted motion tests [Silverstein and Fine, 1984]. Nerve compression disorders required symptoms of numbness or tingling and pain in the nerve distribution on provocative tests with referred pain (e.g., cervical root) ruled out. Estimates of period prevalence (last 12 months) were obtained from interview data, whereas point prevalence estimates were obtained from physical examination plus interview (positive interview and findings at the time of the examination).

Risk factor checklists [Keyserling, 1989; Keyserling et al., 1992, 1993a,b] were completed by ergonomic monitors around the same time the self-administered symptoms questionnaires were completed. Each risk factor was scored: 0 if it was not observed, 1 if it occurred sometimes during the work cycle or day, and 2 if it occurred more than one-third of the cycle or day. Because the checklist was intended to be a sensitive screening tool, monitors were instructed to use the higher score when in doubt. This may have biased the checklist toward false-positives. A priori risk factor summary scores were based on combining risk factors for a

TABLE I. Checklist Risk Factors Used to Create Summary Scores in Study of Ergonomic Risk Factors: Four Automotive Plants, 1987- 1989

Risk factor Neck Shoulder Elbow Wrist Low back

Whole body vibration

Flexion

Extension

Twisting

Stand stationary

Standing foot pedal

No back support

Obstructed lift

Slippery surface

$>$ NIOSH MMH action limit (1981)

Shoulder elevation

Carry $>10 \mathrm{lb}(4.5 \mathrm{~kg})$

Repetitive hand/arm activity

Grip $>6 \mathrm{lb}(2.7 \mathrm{~kg})$ per hand

Pinch grip

Wrist bent

Contact stress

Unbalanced tool

Power tool reactive force

Vibrating power tool

$x \quad x$

$x \quad x$

$\begin{array}{ll}x & x \\ x & x\end{array}$

$x \quad x$

$x$

$x$

$x$

$x$

$X$

$x$

specific body area (neck, shoulder, elbow, hand/wrist, low back), Table I. Where more than one checklist was completed on a specific job, a weighted averaging algorithm, which reflected both the mode for type of exposure and an average score, was used to assign a single score for each risk factor; t-tests were used to compare risk factor scores for those with and without symptoms. Table II summarizes the data collected at different times during the project.

\section{RESULTS}

Six hundred twenty-six active workers (67\% participation) from the eight target departments participated in the baseline university evaluations conducted in 1987 (Table III). Five hundred seventy-nine participated in the 1989 follow-up university evaluations (416 in both baseline and follow-up). Plant seniority, age and gender were similar within departments for those who did and did not participate in the university evaluations. Seven hundred thirteen completed baseline self-administered symptoms questionnaires (75\% participation) within 2-3 months of the university evaluation. We were able to match (social security number or name) 357 who were also identified in the baseline university evaluations. Table III shows the baseline participation rate by plant.

When new health surveillance data sources were compared, baseline prevalence for all body areas was consis- 
TABLE II. Data Collection During the Ergonomic Hazard Surveillance Project

\begin{tabular}{lll} 
Year & Existing data & New data \\
\hline 1986 & All 8 departments: & \\
& OSHA 200 & \\
& Plant medical records & \\
& Workers' compensation & \\
& Plant medical records & \\
& All 8 departments: & Departments 1-4: \\
& OSHA 200 & University examinations \\
& Plant medical records & Symptoms questionnaires \\
& Workers' compensation & Risk factor checklists \\
& Plant medical records & \\
& All 8 departments: & Departments 5- 8: \\
& OSHA 200 & University examinations \\
& Plant medical records & Symptoms questionnaires \\
& Workers' compensation & Risk factor checklists \\
& Plant medical records & \\
All 8 departments: & Departments 1-8: \\
& OSHA 200 & University examinations \\
& Plant medical records & Departments 3, 7: \\
& Workers' compensation & Symptoms questionnaires \\
& Plant medical records & Risk factor checklists
\end{tabular}

TABLE III. Participation in Baseline University Evaluations and Self-Administered Symptoms Questionnaires by Automotive Plant, 1987

\begin{tabular}{|c|c|c|c|c|c|}
\hline \multirow[b]{2}{*}{ Plant } & \multirow[b]{2}{*}{$n$} & \multicolumn{2}{|c|}{$\begin{array}{c}\text { University } \\
\text { examinations }\end{array}$} & \multicolumn{2}{|c|}{$\begin{array}{l}\text { Self-administered } \\
\text { questionnaires }\end{array}$} \\
\hline & & $\mathrm{n}$ & $\%$ & $\mathrm{n}$ & $\%$ \\
\hline 1 & 278 & 151 & 54 & 161 & 58 \\
\hline 2 & 243 & 168 & 69 & 211 & 87 \\
\hline 3 & 258 & 186 & 72 & 252 & 98 \\
\hline 4 & $\underline{169}$ & $\underline{127}$ & 75 & 89 & 53 \\
\hline Total: & 948 & $632^{\mathrm{a}}$ & 67 & 713 & 75 \\
\hline
\end{tabular}

aN includes those who were on employee lists before actual evaluations. Six employees were on layoff or sick leave or were absent or transferred at the time of the evaluation.

tently highest for the university administered interview data (Table IV). Prevalence based on the self-administered symptoms questionnaires was lower and more closely resembled the prevalence data from cases defined by physical examination plus interview. Although $\kappa$ values were low $(0.20-0.40)$ for comparisons of baseline university evaluations and symptoms questionnaires, this primarily reflected finding cases based on university physical examination and interview criteria which were not reported on the symptoms questionnaires.
TABLE IV. Prevalence of Neck, Upper Limb, and Back Disorders by New Surveillance Data Sources: Study of Four Automotive Plants, 1987

\begin{tabular}{|c|c|c|c|c|c|}
\hline Body location/sources & Plant 1 & Plant 2 & Plant 3 & Plant 4 & Total \\
\hline \multicolumn{6}{|l|}{ Neck } \\
\hline Symptoms questa & 3.1 & 8.1 & 12.0 & 4.7 & 8.0 \\
\hline Interview ${ }^{b}$ & 14.5 & 18.8 & 17.8 & 21.5 & 17.9 \\
\hline PE and interviewc & 6.2 & 10.6 & 11.4 & 9.9 & 9.6 \\
\hline \multicolumn{6}{|l|}{ Shoulder } \\
\hline Symptoms questa & 13.0 & 14.7 & 14.0 & 12.8 & 13.9 \\
\hline Interview ${ }^{b}$ & 17.9 & 18.2 & 17.8 & 23.1 & 18.8 \\
\hline $\mathrm{PE}$ and interviewc & 4.8 & 6.5 & 11.4 & 8.3 & 6.5 \\
\hline \multicolumn{6}{|l|}{ Elbow } \\
\hline Symptoms questa & 9.3 & 7.6 & 5.8 & 9.3 & 7.6 \\
\hline Interviewb & 18.6 & 19.4 & 11.9 & 15.7 & 16.3 \\
\hline PE and interviewc & 6.2 & 7.1 & 4.7 & 5.0 & 5.9 \\
\hline \multicolumn{6}{|l|}{ Hand } \\
\hline Symptoms questa & 3.1 & 14.2 & 5.4 & 9.3 & 8.0 \\
\hline Interview ${ }^{b}$ & 33.1 & 28.8 & 25.9 & 30.6 & 29.1 \\
\hline PE and interviewc & 11.0 & 16.7 & 5.9 & 12.4 & 9.4 \\
\hline \multicolumn{6}{|l|}{ Low back } \\
\hline Symptoms questa & 9.3 & 17.1 & 18.2 & 14.0 & 15.6 \\
\hline Interview $^{b}$ & 29.0 & 24.7 & 31.9 & 29.8 & 28.9 \\
\hline $\mathrm{PE}$ and interviewc & 6.9 & 10.0 & 12.4 & 14.9 & 11.0 \\
\hline
\end{tabular}

aSelf-administered questionnaire collected by ergonomics monitor within 2-3 months of university evaluation.

bProbing interview based on previous year's experience conducted by university team.

cPerformed by university researchers; excludes acute trauma, and systemic disease and has positive physical findings.

In Plant 3, 18-month follow-up symptoms questionnaires and university evaluations were available for 80 participants. Estimates of prevalence based on selfadministered symptoms questionnaire were closer to those of university administered detailed interviews than during the baseline period, with $\kappa$ values of $>0.45$ for neck, shoulder, elbow, and hand problems (Table V). The $\kappa$ values were lower comparing symptoms questionnaires to physical examination plus interview. This largely reflects the difference between period prevalence (symptoms questionnaires and interviews) and point prevalence (positive also at the time of physical examination). In general, sensitivity was relatively high $(0.78-0.88)$, but specificity $(0.21-0.38)$ and positive predictive value $(0.31-0.50)$ were found to be low when the symptoms questionnaire was compared to the physical examination plus interview.

Of the 713 participants who completed the initial symptoms questionnaires, 278 (39\%) reported receiving treatment for their musculoskeletal disorder in the previous year. Of these, $150(54 \%)$ reported that their treatment was received at the plant medical/first-aid department. Of those reporting they had gone to the medical department, medical records abstraction by university personnel identified related 
TABLE V. Comparison of Follow-up Prevalence of Symptoms Between University Evaluations and Among Automotive Workers: Self-Administered Symptoms Questionnaires, Plant $3(n=80), 1989^{a}$

\begin{tabular}{lccccc} 
& $\begin{array}{c}\text { Symptoms } \\
\text { questionnaire } \\
\text { Body location }\end{array}$ & $\boldsymbol{\kappa}^{\mathrm{b}}$ & $\begin{array}{c}\text { University } \\
\text { interview } \\
(\%)\end{array}$ & $\boldsymbol{\kappa}^{\mathrm{c}}$ & $\begin{array}{c}\text { University } \\
\text { inteview and PE } \\
\mathbf{P E}(\%)\end{array}$ \\
\hline Neck & 41.3 & 0.49 & 46.3 & 0.43 & 25.0 \\
Shoulder & 35.0 & 0.55 & 32.5 & 0.36 & 13.8 \\
Elbow & 12.5 & 0.47 & 15.0 & 0.47 & 12.5 \\
Hand/wrist & 45.0 & 0.53 & 28.8 & 0.42 & 10.0 \\
Low back & 42.5 & 0.33 & 42.5 & 0.23 & 11.3 \\
\hline
\end{tabular}

${ }^{a_{\mathrm{K}}}$ estimates interrater agreement; $0.40-0.75$ considered fair to good agreement. ${ }^{b}$ Agreement between symptoms questionnaire and university interview.

cAgreement between symptoms questionnaire and university interview.

medical records entry for only $41 \%$. Results varied by plant: 15\% (Plant 4), 26\% (Plant 2), 39\% (Plant 1), and 61\% (Plant 3).

In order to assess the "capture" of cases by the plant medical departments, medical records were abstracted for the previous 4 years for those who participated in the follow-up university evaluations in 1989 (Table VI). It was expected that the medical personnel would have improved record keeping by this time since the ergonomic programs had been in place for 18 months and a computerized medical $\log$ had been implemented the previous year [1988]. However, there was considerable underreporting to or by the medical departments. For example, 210/579 (36\%) met the criteria for low back disorders on university interview, $65 / 579$ (11\%) were positive on both physical examination and interview, and 64/579 (11\%) reported having gone to the plant medical department for treatment in the previous year. Only 11 of the latter group were found to be recorded by medical personnel in the first-aid dispensaries and none were recorded in the main medical department. While some who did not report having gone to first-aid/plant medical were recorded as having been seen, the numbers were small (1-5.5\% of the 579$)$.

Usually, the most easily accessible existing surveillance data include OSHA 200 logs, workers' compensation and sickness and accident benefit data (personal medical benefits). "Incidence" rates were calculated based on year of first report between January 1, 1986 and December 30, 1988 per 100 worker-years. The "incidence" rate for those who self-reported receiving medical treatment for a problem within the year before completing the baseline symptoms questionnaire was compared to department-wide OSHA 200 log rates for 1986-1988 (Table VII). The rate based on self-reported treatment was considerably higher than that based on the OSHA $200 \mathrm{log}$. To some extent, this may have been due to nonreporting to the plant medical department. If it is assumed that one-half of those receiving medical
TABLE VI. Prevalence of Musculoskeletal Disorders on University Follow-up Evaluations Compared to Those Seen at Automotive Plant Medical Facilities $(n=579), 1989$

\begin{tabular}{|c|c|c|c|c|}
\hline \multirow[b]{2}{*}{ Body location/sources } & \multicolumn{2}{|c|}{$\begin{array}{l}\text { University } \\
\text { evaluations }\end{array}$} & \multicolumn{2}{|c|}{$\begin{array}{c}\text { Plant medical } \\
\text { records }^{a}\end{array}$} \\
\hline & n & $\%$ & $\mathbf{n}$ & $\%$ \\
\hline \multicolumn{5}{|l|}{ Neck } \\
\hline Interview & 187 & 31.4 & 6 & 1.0 \\
\hline Interview and PE & 97 & 16.8 & 6 & 1.0 \\
\hline $\begin{array}{l}\text { Reported going to plant } \\
\text { department }\end{array}$ & 43 & & 3 & \\
\hline \multicolumn{5}{|l|}{ Shoulder } \\
\hline Interview & 159 & 27.5 & 15 & 2.6 \\
\hline Interview and PE & 59 & 10.2 & 15 & 2.6 \\
\hline $\begin{array}{l}\text { Reported going to plan } \\
\text { department }\end{array}$ & 31 & & 4 & \\
\hline \multicolumn{5}{|l|}{ Elbow } \\
\hline Interview & 108 & 18.7 & 15 & 2.6 \\
\hline Interview and PE & 68 & 11.9 & 15 & 2.6 \\
\hline $\begin{array}{l}\text { Reported going to plan } \\
\text { department }\end{array}$ & 17 & & 3 & \\
\hline \multicolumn{5}{|l|}{ Hand/wrist } \\
\hline Interview & 222 & 38.7 & 15 & 2.6 \\
\hline Interview and PE & 62 & 10.7 & 15 & 2.6 \\
\hline \multicolumn{5}{|c|}{ Reported going to plant medical } \\
\hline \multicolumn{5}{|l|}{ Back } \\
\hline Interview & 210 & 36.3 & 32 & 5.5 \\
\hline Interview and PE & 65 & 11.2 & 32 & 5.5 \\
\hline $\begin{array}{l}\text { Reported going to plant } \\
\text { department }\end{array}$ & 64 & & 11 & \\
\hline
\end{tabular}

aMedical records abstracted through 4 years before the 1989 university evaluation.

treatment went to non-plant medical practitioners, the two rates become more nearly equal in most of the plants by 1988. However, there still appears to have been underreporting on the OSHA log. The pattern of increasing rates between 1986 and 1988 for the OSHA $200 \log$ may represent changes in administrative policy rather than actual incidence.

The incidence rate for those who reported a problem resulting in lost time within the year prior to completing the symptoms questionnaire was compared to department-wide workers compensation and sickness and accident rates (Table VIII). Self-reported lost time rates were comparable to workers' compensation rates but interplant variability in results makes generalization difficult.

Finally, data from self-administered symptoms questionnaires were compared to active "hazard" surveillance checklists [Keyserling, 1989; Keyserling et al., 1992, 1993a,b] for associations with potential work-related risk factors. Risk 


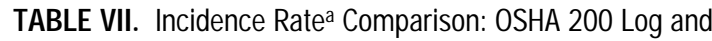
Self-Reported Medical Treatment: Study at Four Automotive Plants, 1986-1988

\begin{tabular}{ccc} 
Plant/years & OSHA 200 log & $\begin{array}{c}\text { Self-reported } \\
\text { medical treatment }\end{array}$ \\
\hline Plant 1 & & \\
1986 & 1.0 & \\
1987 & 2.7 & \\
1988 & 6.9 & \\
Plant 2 & & \\
1986 & 0.9 & 40.9 \\
1987 & 11.9 & \\
1988 & 21.4 & \\
Plant 3 & & \\
1986 & 20.3 & \\
1987 & 14.6 & \\
1988 & 19.3 & \\
Plant 4 & & \\
1986 & 0.7 & 24.5 \\
1987 & 2.1 & \\
1988 & 9.9 & \\
\hline
\end{tabular}

aCalculated per 100 worker years.

bReported receiving medical treatment within the year prior to completing the selfadministered symptoms questionnaire; questionnaires completed between May 1987 and May 1988.

TABLE VIII. Incidence Rate Comparison: Workers' Compensation, Sickness and Accident and Self-Reported Lost Time: Four Automotive Plants, 1986-1988

\begin{tabular}{cccc} 
& $\begin{array}{c}\text { Workers' } \\
\text { compensation }\end{array}$ & $\begin{array}{c}\text { Sickness } \\
\text { and accident }\end{array}$ & $\begin{array}{c}\text { Self-reported } \\
\text { lost time }^{b}\end{array}$ \\
\hline Plant 1 & & & \\
1986 & 7.4 & 13.4 & 0.0 \\
1987 & 3.4 & 11.4 & \\
1988 & 2.2 & 9.1 & \\
Plant 2 & & & \\
1986 & 3.5 & 14.8 & \\
1987 & 2.5 & 17.7 & \\
1988 & 5.1 & 9.2 & \\
Plant 3 & & & \\
1986 & 9.3 & 25.6 & \\
1987 & 9.6 & 22.4 & \\
1988 & 7.1 & 12.0 & \\
Plant 4 & & & \\
1986 & 1.7 & 6.0 & \\
1987 & 4.9 & 4.8 & \\
1988 & 4.0 & 4.0 & \\
\hline
\end{tabular}

${ }^{a}$ Calculated per 100 worker-years.

${ }^{b}$ Reported lost time within the year before completing the self-administered symptoms questionnaire; questionnaires completed between May 1987 and May 1988. factor checklists were available for the jobs of 676 individuals who completed the baseline symptoms questionnaire. Comparable data were available for 357 of them who also participated in the university evaluations. Table IX shows the summary risk factor scores for different body areas based on self-administered symptoms questionnaire and university interview and physical examination status. For the most part, those with symptoms or disorders had higher relevant risk factor scores than were recorded for those who did not and these scores were similar across the two new health data sources. The mean summary wrist score was significantly higher for positive cases whether determined by university administered interview and physical examination or the self-administered symptoms questionnaire.

\section{DISCUSSION}

The magnitude of work-related musculoskeletal disorders was considerably greater using new surveillance techniques such as self-administered symptoms questionnaires and university evaluations than based on surveillance using pre-existing plant health data sources. Despite a less restrictive case definition (acute traumatic onset/related systemic disease not excluded), the baseline symptoms questionnaires did not include about $20 \%$ of the positive cases identified by university examinations. This may have been due to the episodic nature of these disorders in an actively working population. In the absence of lost work time, a problem reported to a university interviewer may not have been remembered when completing a self-administered questionnaire several months later. Questionnaire design may also have played a role. The university interview asked about the presence of symptoms for each body area whereas the self-administered questionnaire recorded symptoms for only the most severe problem. On the other hand, there may have been distrust of the use of the data gathered by coworkers or embarrassment about reporting symptoms to coworkers. The closer approximation of incidence of WMD to university interview results for the follow-up in Plant 3 suggests that some increased level of confidence in the process may have taken place (Table V). This would be consistent with a change in union and management attitude from lukewarm support to much more enthusiastic endorsement. For example, by the time of the follow-up, supervisor performance evaluations had been changed to include an assessment of whether or not ergonomic problems had been addressed. A learning process had also occurred. By the time of follow-up, employees were aware of the ergonomic program, the role of the ergonomic monitors, and the fact that there had been no adverse impact on them as a result of their participation.

Nonetheless, positive predictive value of the symptoms questionnaire was low when comparing it to physical examination plus interview. Depending on the "cut points" for inclusion as a case using symptoms data (e.g., combina- 
TABLE IX. J ob Checklist of Ergonomic Risk Factors Compared to Self-Administered Symptoms Questionnaire and University Evaluations in Four Automotive Plants: Mean Summary Score by Body Area, 1987

\begin{tabular}{|c|c|c|c|c|}
\hline \multirow[b]{2}{*}{ Checklist risk factor } & \multicolumn{2}{|c|}{$\begin{array}{l}\text { University evaluation } \\
\qquad(\mathrm{n}=337)\end{array}$} & \multicolumn{2}{|c|}{$\begin{array}{l}\text { Self-administered questionnaire } \\
\qquad(n=676)\end{array}$} \\
\hline & Yes $^{\mathrm{a}}$ & No & Yes $^{\mathrm{b}}$ & No \\
\hline Shoulder score $(\max =8)(\mathrm{SD})$ & $1.40 \pm 1.11$ & $1.54 \pm 1.11$ & $1.54 \pm 1.18$ & $1.45 \pm 1.11$ \\
\hline Elbow score $(\max =18)(S D)$ & $6.52 \pm 2.11$ & $5.73 \pm 2.19$ & $6.00 \pm 2.02^{c}$ & $5.49 \pm 2.00$ \\
\hline Wrist score (max = 18) (SD) & $6.54 \pm 2.05^{c}$ & $5.55 \pm 2.18$ & $6.20 \pm 2.68^{d}$ & $5.30 \pm 1.83$ \\
\hline Back score $(\max =20)(S D)$ & $4.81 \pm 1.69$ & $4.69 \pm 1.98$ & $4.76 \pm 1.91$ & $4.62 \pm 2.03$ \\
\hline
\end{tabular}

aPositive case if symptoms occurred $\geq 20$ times in previous year or lasted $\geq 1$ week and no acute trauma, no related systemic disease and positive physical examination findings.

bPositive case if occurred $\geq 20$ times in previous year or lasted $\geq 1$ week.

$c p<0.05$.

dp $<0.01$.

tions of frequency, intensity and duration of symptoms), one could alter sensitivity and specificity [Baron et al., 1992]. This may be important to do in prioritizing jobs for intervention.

The prevalence of self-reported symptoms was high in this population, compared to National Health Interview Survey (NHIS) data from 1988 [Behrens et al., 1994]. For example, period prevalence (past 12 months) of back pain from repeated activities at work lasting more than one week was 5.8\% among assemblers, $6.5 \%$ among machine operators, compared to $15.6 \%$ on symptoms questionnaire and $28.9 \%$ on university-administered interview in this study population. Hand pain in the NHIS data was estimated to be $21.9 \%$ for assemblers and $23 \%$ for machine operators, as compared to $8 \%$ on the symptoms questionnaire and $29.1 \%$ on university-administered interview (Table IV). It may be that the current study population jobs were considerably heavier than more generic "assembly and machine operator jobs." At the same time, workers' compensation rates seem to be similar to those reported in the literature [Guo et al., 1995].

According to Dickinson et al. [1992], the way in which a symptoms questionnaire is administered has an effect not only on response rate but also on prevalence rate. When their questionnaire was administered by researchers, there was a higher response rate but lower prevalence rate than when self-administered. They conclude that self-administered questionnaires tend to be returned primarily by those who have a problem. In the current study, it appeared that those with more problems (identified on university examination) may have been less willing to indicate problems on the symptoms questionnaire. This difference may again relate to concerns about confidentiality. In the Dickinson study, "assurances of confidentiality" were made in a cover letter and each self-administered questionnaire was returned to the researchers in a sealed envelope. This is in contrast to our study in which the university evaluations were stored and processed at the university while self-administered questionnaires were collected and processed by non-university personnel and stored at the plants.

The use of multiple methods of conducting surveillance in these plants for WMD provided an opportunity to evaluate qualitatively the strengths and weaknesses of the different types of surveillance data. Surveillance derived from existing records systems have the advantage of availability and acceptance by plant culture. The disadvantage of using workers' compensation and sickness and accident data sources for surveillance is that cases are not detected until the problem has become severe. For example, the mean cost of back and upper limb compensation claims has been estimated to be more than $\$ 8,000$ in direct costs [Webster and Snook, 1994a \& b]. Those claims resulting in lost time are usually more costly. In addition to other limitations [Korrick et al., 1994], workers' compensation policy varies considerably by state and therefore cannot provide a consistent surveillance database. While this was not a problem in this study, comparison of workplaces within the same company but different states, makes interpretation difficult. Sickness and accident data have the limitation of potentially mixing work-related and non-work-related cases. The OSHA $200 \log$ could theoretically provide a more timely surveillance source for early identification of problems. However, maintenance of the log is strongly affected by management policy and personnel training. While it is possible that those who completed the self-administered questionnaire were more likely to have WMDs than the department as a whole, it is unlikely that this possible bias is a sufficient explanation for all the difference between "incidence" rates for selfreported medical treatment versus the OSHA $200 \log$ (Table VII). For the study plants, the self-administered symptoms questionnaire seems to have been a much more sensitive surveillance tool than the OSHA $200 \mathrm{log}$. In addition, since the OSHA $200 \log$ is not required for 22 Standard Industrial 
Codes or for small employers, its value as a national surveillance tool is limited.

While plant medical records, particularly those which capture initial visits, have the potential to be a sensitive indicator of current symptom prevalence, workers who seek treatment elsewhere will be missed. That this can be a sizable proportion was found to be the case; nearly one-half (46\%) of those completing the baseline symptoms questionnaire who reported having received medical treatment went to nonplant health practitioners. Others have found evidence of underreporting in a population where $59 \%$ of evaluated workers had objective signs of upper extremity functional impairment, but only $14 \%$ had reported a problem to the plant nurse within the prior year [Higgs et al., 1992]. In our study, neither plant medical or first-aid records were able to identify $59 \%$ of those who reported going to the medical department for treatment. In addition to having sought treatment elsewhere, possible explanations for the discrepancies in reporting include the following:

- Workers went to the medical department but received no or minimal treatment and were not recorded.

- Plant medical personnel decided the problems were not work related and did not feel a need to record them.

- Workers who may have sought treatment for multiple purposes may not have had the problem of interest recorded.

- Workers may have been inaccurate in their recollection.

Although nursing staff comments and concerns were incorporated into the development of the software system for recording medical visits, minimal training was provided regarding classification issues related to body location and type of disorder, nor were nurses trained in how to retrieve the information they might need for other than tracking purposes. Nursing staff may have been unwilling to use the new computerized system regularly, reducing the likelihood of data entry. It is possible that more "user-friendly" interfaces [Goldberg et al., 1993] would find more acceptability by nursing staff than with the system used in this study. Except for Plant 3, nursing staff were largely peripheral to the ergonomic program process. Integrating nursing staff into the ergonomic program may result in better record keeping as well.

Symptoms questionnaires appeared to be a more sensitive indicator of musculoskeletal problem prevalence than plant medical records and certainly more than other preexisting surveillance sources (Tables VI-VIII). Although we do not know whether these findings are applicable to other facilities and industries, we believe that they may be. The university-conducted interview and physical examination was sensitive and, because of efforts to standardize data collection, provided the most consistent results. However, these examinations were relatively expensive and if implemented more widely would require training of interview/ examination teams. Symptoms questionnaires seem similarly sensitive and are less expensive. Symptoms questionnaires will require the use of internal comparison groups in most facilities to effectively identify high risk jobs. The success of any surveillance system that requires involvement of workers and front-line supervisors in conducting either symptoms questionnaires or hazard surveillance will depend on a number of factors:

- The past plant history of employee involvement programs

- The process by which ergonomic monitors, or their equivalent, are selected

- The training of those charged with administering the symptoms questionnaire and risk factor checklist

- Worker perception of confidentiality of symptoms questionnaire (may be especially sensitive issue if layoffs are anticipated)

- Organizational support for data collection, analysis, and timely reporting

- Awareness of employees about the purpose of the surveillance system and their willingness to report symptoms to coworkers or supervisors

- The degree to which employees see some positive response to the information they have provided

- The degree to which symptoms prevalence and severity, as well as their correlation to potential risk factors, can be used to prioritize jobs for intervention

Hazard surveillance is a useful approach independent of its role in supplementing a health surveillance system because potential hazards can be detected in small groups of workers in situations where health surveillance (reliance on a proportion of workers with symptoms) is less effective. Symptomatic workers had jobs with more exposure to risk factors than non-symptomatic workers. This was true whether cases were defined by the university interview plus physical examination or the self-administered symptoms questionnaire. While not all observed differences were significantly different, several factors may have resulted in misclassification. These include extrapolation of the checklist risk factor data to workers not directly observed, possible error introduced by the method of weighted averaging of checklists to create a single score for each job, and the built-in checklist bias toward overestimation of exposure potentially underestimating associations. Other evaluations of the risk factor checklist system suggest that it is valid [Keyserling, 1989, 1992, 1993a,b]. The individual risk factor scores that make up the summary score may be more useful in prioritizing jobs for intervention. A combination of hazard and health surveillance tools should be used to prioritize jobs for further evaluation and intervention within workplace ergonomics programs. The continuing use of these instruments throughout the corporation suggests that they are useful for local ergonomics committees. 


\section{CONCLUSIONS}

Without a "gold standard" for surveillance of WMDs, it is difficult to estimate the true magnitude of those affected or to effectively evaluate change. Because work methods and postures may vary considerably between individuals doing the "same" job [Hammarskjold et al., 1989; Keyserling et al., 1993b], the ideal evaluation method would be to perform simultaneously a risk factor checklist and complete a symptoms questionnaire for each worker. Higgs et al. [1992] found that reliance on self-reported symptoms underestimated the prevalence of those with objective signs of upper extremity impairment and they recommended the use of screening batteries that include objective measures. However, such resource intensive methods have a high cost. The self-administered symptoms questionnaire is relatively inexpensive and appears to be a reliable surveillance tool for tracking early symptoms of WMDs. Within the context of a plant ergonomic program strongly supported by all leaders, and with adequate training for and integration of all plant members, the symptoms questionnaire and risk factor checklist could be used to identify and track symptomatic individuals and work-related risk factors. Changes in sensitivity and specificity can be achieved by altering the cutpoints (frequency, intensity, and duration of symptoms) for determining a case definition. A standardized symptoms questionnaire could provide the basis for an ongoing surveillance system. In conjunction with a standardized hazard surveillance system, this could be used to evaluate the effects of exposure reduction on the development of WMDs.

\section{REFERENCES}

Armstrong TJ, Fine LJ, Goldstein SA, Lifshitz YR, Silverstein B (1987): Ergonomics considerations in hand and wrist tendinitis. J Hand Surg 12A:830-837.

Armstrong TJ, Buckle P, Fine LJ, Hagberg M, Jonsson B, Kilbom A, Kuorinka IAA, Silverstein BA, Sjogaard G, Viikari-Juntura ERA (1993): A conceptual model for work-related neck and upper-limb musculoskeletal disorders. Scand J Work Environ Health 19:73-84.

Baron S, Hales T, Fine L (1992): Evaluation of a questionnaire to assess the prevalence of work-related musculoskeletal disorders. International Scientific Conference on Prevention of Work-related Musculoskeletal DisordersPREMUS: pp. 39-41. Sweden, May 12-14, 1992.

Behrens V, Seligman P, Cameron L, Mathias T, Fine L (1994): The prevalence of back pain, hand discomfort, and dermatitis in the US working population. Am J Public Health 84:1780-1785.

Bureau of Labor Statistics (1995): "Survey of Occupational Injuries and Illnesses, 1991.” Washingtion, DC: US Department of Labor.

Dickinson CE, Campion K, Fostyer AF, Newman SJ, O'Rourke AMT, Thomas PG (1992): Questionnaire development: An examination of the Nordic musculoskeletal questionnaire. Appl Ergon 23:197-201.

Goldberg JH, Leader BK, Stuart-Buttle C (1993): Medical logging and injury surveillance database system. Int J Ind Ergon 11:107-123.

Guo HR, Tanaka S, Cameron L, Seligman P, Beherns V, Ger J, Wild D, Putz-Anderson V (1995): Back pain among workers in the United States: national estimates and workers at high risk. Am J Ind Med 28:591-502.
Hagberg M, Morgenstern H, Kelsh M(1992): Impact of occupations and job tasks on the prevalence of carpal tunnel syndrome. Scand J Work Environ Health 18:337-345.

Hagberg M, Wegman DH (1987): Prevalence rates and odds ratios of shoulder neck diseases in different occupational groups. Br J Ind Med 44:602-610.

Hagberg M, Silverstein B, Wells R, Smith M, Hendrick H, Cararyon P, Perusse M (1995): Chapter 4 Identification, measurement and evaluation of risk pp 139-212. In Kuorinka, Forcier (eds): Work-Related Musculoskeletal Disorders-A Manual for Prevention. Taylor \& Francis, London.

Hammarskjold E, Ekholm J, Harms-Ringdahl K (1989): Reproducibility of work movements with carpenters' hand tools. Ergonomics 32:1005-1018.

Higgs P, Young VL, Seaton M, Edwards D, Feely C (1992): Upper extremity impairment in workers performing repetitive tasks. Plast Reconstr Surg 90:614-620.

Keyserling WM (1989): Analysis of manual lifting tasks: A qualitative alternative to the NIOSH work practices guide. Am Ind Hyg Assoc J 50:165-173.

Keyserling WM, Brouwer M, Silverstein BA (1992): A checklist for evaluating ergonomic risk factors resulting from awkward postures of the legs, trunk, and neck. Int J Ind Ergon 9:283-301.

Keyserling WM, Brouwer M, Silverstein BA (1993a): The effectiveness of a joint labor-management program in controlling awkward postures of the trunk, neck and shoulders: Results of a field study. Int J Ind Ergon 11:51-65.

Keyserling WM, Stetson DS, Silverstein BA, Brouwer M (1993b): A checklist for evaluating ergonomic risk factors associated with upper extremity cumulative trauma disorders. Ergonomics 36:807-831.

Korrick SA, Rest KM, Davis LK, Christiani DC (1994): Use of state workers' compensation data for occupational carpal tunnel syndrome surveillance: A feasibility study in Massachusetts. Am J Ind Med 25:837850 .

Kuorinka I, Jonsson B, Kilbom A, Vinterberg H, Biering-Sorenson F, Andersson G, Jorgensen K (1987): Standardized Nordic questionnaires for the analysis of musculoskeletal symptoms. Appl Ergon 18:233-237.

Moore JS (1992): Carpal tunnel syndrome. Occup Med:STAR 7:741-763.

Pollack ES, Keimig DG (1991): "Counting Injuries and Illnesses in the Workplace: Proposals for a Better System." Washington, DC: National Academy Press.

Rempel DM, Harrison RJ, Barnhardt S (1992): Work-related cumulative trauma disorders of the upper extremity. JAMA 267:838-842.

Silverstein BA, Fine LJ (1984): "Evaluation of Upper Extremity and Low Back Cumulative Trauma Disorders-A Screening Manual." Ann Arbor: The University of Michigan School of Public Health.

Silverstein BA, Fine LJ, Armstrong TJ (1987): Occupational factors and carpal tunnel syndrome. Am J Ind Med 11:343-358.

Snook SH (1978): The design of manual handling tasks. Ergonomics 21:963-985.

Sommerich CM, McGlothlin JD, Marras WS (1993): Occupational risk factors associated with soft tissue disorders of the shoulder: A review of recent investigations in the literature. Ergonomics 36:697-717.

Stenlund B, Goldie I, Hagberg M, Hogstedt C (1993): Shoulder tendinitis and its relation to heavy manual work and exposure to vibration. Scand J Work Environ Health 19:43-49.

Webster B, Snook S (1994): The cost of 1989 workers' compensation lowback pain claims. Spine 19:1111-1115.

Webster B, Snook S (1994): The cost of compensable upper extremity cumulative trauma disorders. J Occup Med 36:713-717. 